\title{
DESCRIÇÕES DE OITO NOVAS ESPÉCIES DE AMBLYCERUS THUNBERG (COLEOPTERA, BRUCHIDAE) ${ }^{1}$
}

\author{
Cibele S. Ribeiro-Costa ${ }^{2}$
}

\begin{abstract}
Descriptions of EigitT NEW SPECIES of Amblycerus Tilunberg (COleOPTERA, BRUCHIDAE). The following new seed beetles are described and illustrated: Amblycerus virescens sp.n., A. viridans sp.n., A. viridis sp.n., A. megalobus sp.n., A. atrogaster sp.n., A. chapadicola sp.n., A. mourei sp.n. and $A$. danunciae sp.n.. These species are recorded from Brazil and one of them also recorded from Bolivia.

KEY WORDS. Coleoptera, Bruchidae, Amblycerus, new species
\end{abstract}

Dando continuidade às descrições de novas espécies em Amblycerus Thunberg, 1815 (Kingsolver 1991; Ribeiro-Costa \& Kingsolver 1993a,b; RIBEIRO-COSTA 1993) acrescenta-se ao gênero mais oito espécies brasileiras, sendo que uma delas também ocorrente na Bolívia.

\section{MATERIAL E MÉTODOS}

O material examinado pertence às seguintes instituições: Museu de Zoologia, Universidade de São Paulo, São Paulo (MZSP); Museu Paraense Emílio Goeldi, Belém (MPEG); Coleção de Entomologia Pe. Jesus S. Moure, Curitiba (DZUP); Fundação Instituto Oswaldo Cruz, Rio de Janeiro (FIOC); Carnegie Museum of Natural History, Pittsburgh (CMNH); National Museum of Natural History, Washington (USNM); Museum of Comparative Zoology, Cambridge (MCZC).

Nas descrições o termo "rufo" refere-se à coloração arruivada; testáceo, a castanho-escuro ou bordô; flavo, a amarelo ou cor de palha e fulvo, a amarelo-escuro. Os índices foram obtidos a partir de mensurações como indicadas nas ilustrações da primeira espécie descrita (Figs 1a,b, 2a,b; 3a,b; 5a,b; 8a-e) e, o número de omatídios, a partir de contagem em uma área de $0,006 \mathrm{~mm}^{2}$, com aumento de $50 \mathrm{X}$ em estereomicroscópio. Os escleritos do saco interno do lobo médio da terminália do macho são descritos na sua posição evertida conforme KINGSOLVER (1970).

Após a extração e clarificação da terminália do macho, as diferentes partes foram separadas, colocadas sobre lâmina contendo uma gota de glicerina e desenhadas esquematicamente sob estereomicroscópio para registrar, antes do manuseio, a posição dos escleritos do saco interno do lobo médio. Em seguida, as estruturas foram desenhadas detalhadamente ao microscópio. Sob o estereomicroscópio, foram destacados os escleritos do saco interno e desenhados ao microscópio,

1) Contribuição número 989 do Departamento de Zoologia, Universidade Federal do Paraná.

2) Departamento de Zoologia, Universidade Federal do Paraná. Caixa Postal 19020, 81531-990 Curitiba, Paraná, Brasil. 
frequentemente em mais de uma posição. Alguns escleritos, por serem volumosos, foram ainda transferidos para uma lâmina escavada contendo glicerina e algumas fibras de algodão, para facilitar a acomodação dos escleritos na posição desejada. $\mathrm{O}$ desenho de cada esclerito foi feito com mesmo aumento utilizado para as outras partes do lobo médio.

Com os contornos do lobo médio, do saco interno e dos escleritos obtidos isoladamente, fez-se uma composição. Os escleritos foram posicionados no saco interno nos locais em que haviam sido observados, logo após o processo de clarificação, sob o estereomicroscópio.

Quando a terminália de todos os exemplares da espécie encontrava-se com o saco interno protraído, a terminália foi ilustrada nesta forma e, à parte, foi composta outra ilustração com a provável posição dos escleritos, se o saco interno estivesse retraído.

Foram estudados, quando disponíveis, dois machos de cada espécie a fim de confirmar a posição dos escleritos e de verificar a existência de variabilidade intraespecífica em caracteres internos. Quando se verificavam variações, um maior número de exemplares machos foi dissecado.

\section{RESULTADOS E DISCUSSÃO}

As espécies aqui descritas, Amblycerus virescens sp.n., $A$. viridans sp.n., $A$. viridis sp.n., A. megalobus sp.n., A. atrogaster sp.n., A. chapadicola sp.n., $A$. mourei sp.n. e A. danunciae sp.n., assemelham-se pelos seguintes caracteres:

Carena frontal ausente. Antena (Fig. 3) serreada a partir do quinto artículo; oitavo, nono e décimo artículos mais largos que longos; último artículo subgloboso. Pronoto semicircular com margens laterais moderadamente arqueadas em vista dorsal, sem sulco cervical e sulco junto à borda posterior; carena lateral (Figs 4, 17) longa, muito além da metade do comprimento lateral do pronoto, bifurcada anteriormente. Processo prosternal delgado. Élitros convexos ao longo da sutura elitral, arredondados apicalmente. Metepisterno (Fig. 6) com pontos grossos adensados; sem área fusiforme transversalmente estriada. Coxa posterior (Fig. 7) com pontos grossos, exceto no terço basal. Porção distal da margem ventral do fêmur posterior, não denteada. Tíbia posterior com espinhos coronais aproximadamente de mesmo tamanho (Fig. 8); face ventral plana com linha de pontos e cerdas grossa conspícua nas margens. Pigídio arredondado apicalmente.

Terminália do macho. Oitavo tergito arredondado apicalmente. Lobo médio (Fig. 9) com a valva ventral moderadamente longa, afilada apicalmente; valva dorsal subtriangular. Região apical do saco interno com dentículos próximo ao esclerito apical.

\section{Amblycerus virescens sp.n.}

Figs 1-10

Dimensões. Comprimento 4,83-6,00mm $(\overline{\mathrm{x}}=5,50 \mathrm{~mm} ; \mathrm{n}=6)$; largura 3,25$4,25 \mathrm{~mm}(\overline{\mathrm{x}}=3,83 \mathrm{~mm} ; \mathrm{n}=6)$. 

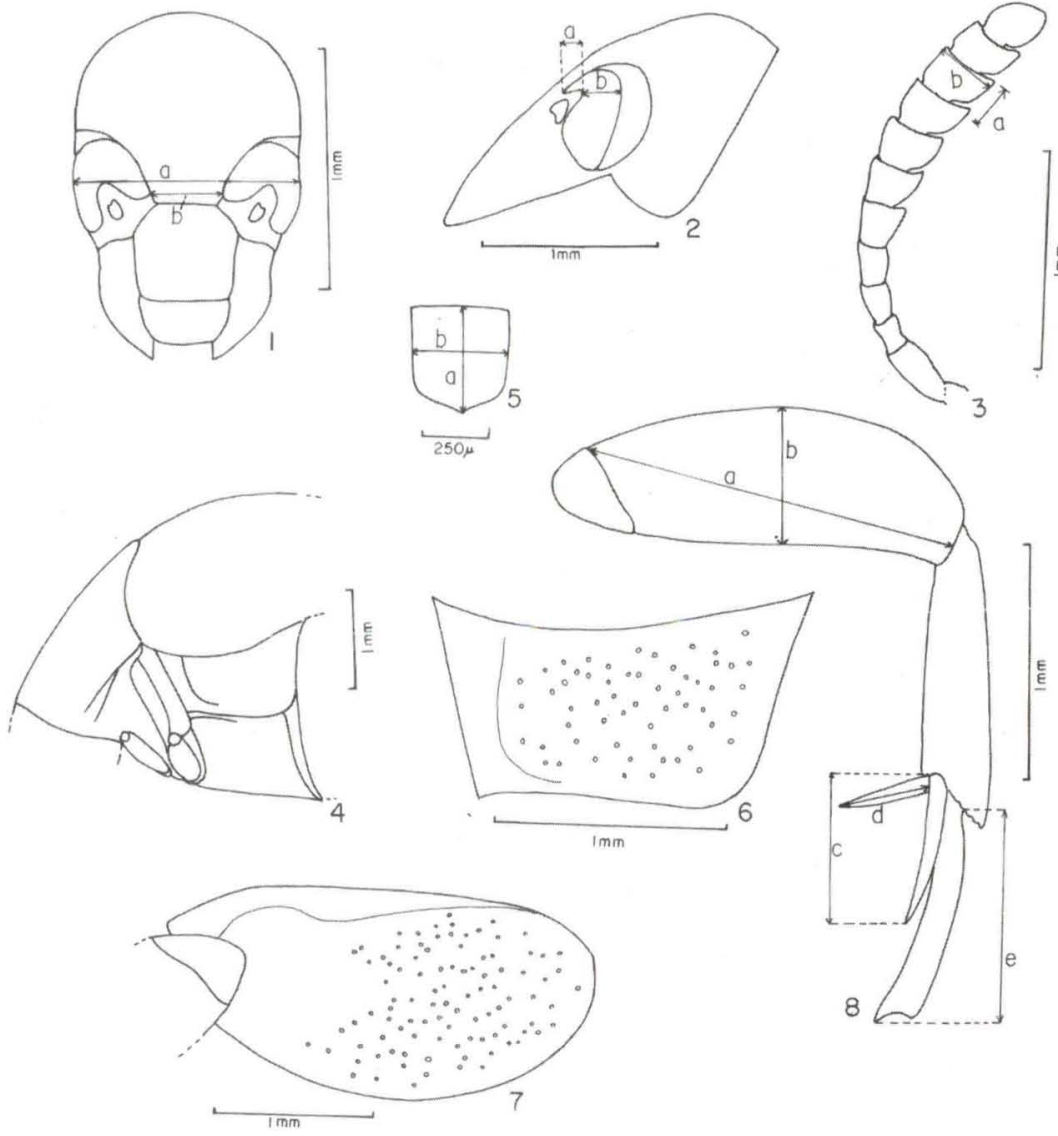

Figs 1-8. Amblycerus virescens sp.n. (1) Cabeça, vista frontal: (a) maior distância interorbital, (b) menor distância interorbital; (2) cabeça, vista lateral: (a) comprimento do sinus ocular, (b) comprimento do olho; (3) antena: (a) comprimento do nono artículo, (b) largura do nono articulo; (4) tórax em vista lateral; (5) escutelo: (a) comprimento, (b) largura; (6) metepisterno; (7) coxa posterior; (8) perna posterior: (a) comprimento do fêmur, (b) largura do fêmur, (c) comprimento do esporão lateral, (d) comprimento do esporão mediano, (e) comprimento do primeiro tarsômero.

Tegumento. Coloração geral preta exceto pigídio e abdome, rufos. Algumas vezes os dois primeiros artículos antenais mais claros.

Pilosidade. Maior parte do corpo com pilosidade verde; pêlos pretos isolados, dispersos. Pigídio e abdome flavos com brilho dourado.

Fronte levemente achatada. Olhos finamente facetados (10 omatídios), não protraídos lateralmente (Fig. 1); índice ocular 3,4 (Fig. 1); sinus ocular 1/2,0 o diâmetro do olho em vista lateral (Fig. 2); lobo pós-ocular 1/1,6 vezes o maior comprimento do olho em vista lateral (Fig. 2). Oitavo, nono e décimo artículos 

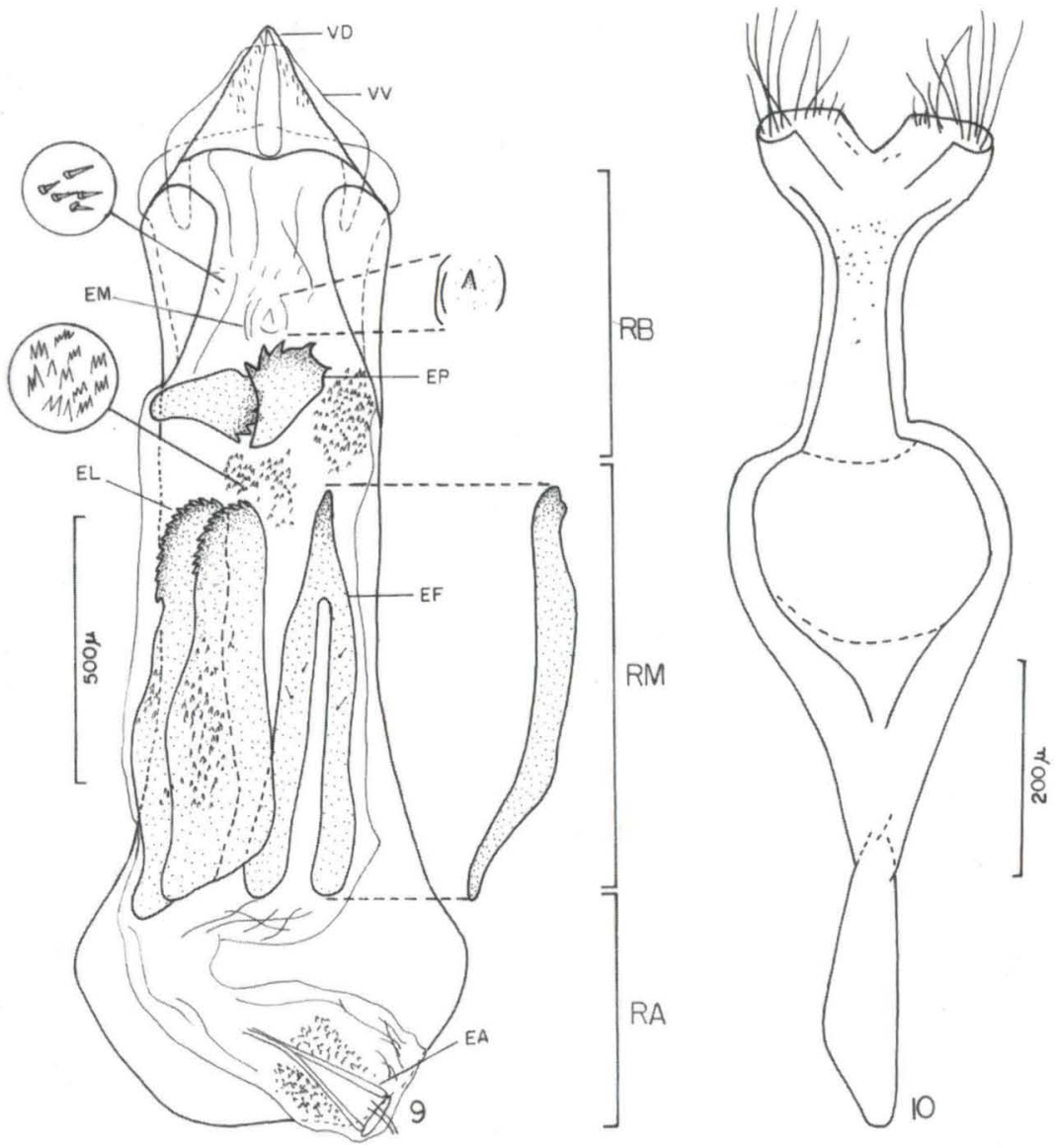

Figs 9-10. Amblycerus virescens sp.n. Terminália do macho. (9) Lobo médio (10) tégmen. (RA) Região apical do saco interno, (RM) região mediana do saco interno, (RB) região basal do saco interno, (VD) valva dorsal, (VV) valva ventral, (EM) esclerito médio, (EP) esclerito posterior, (EL) esclerito lateral, (EF) esclerito em forma de forquilha, (EA) esclerito apical.

antenais cerca de 0,7 vezes tão longo quanto largo (Fig. 3). Disco do pronoto sem pontos grossos. Processo prosternal levemente expandido além das coxas anteriores. Escutelo (Fig. 5) tão longo quanto largo, com ápice levemente unidentado ou arredondado. Élitros com estrias medianas fracamente impressas, principalmente na metade apical. Eixo transversal do sulco metepisternal divergindo dorsalmente, eixo longitudinal muito curto, menos que a metade do comprimento do metepisterno (Fig. 6). Metasterno não protuberante em vista lateral na região das coxas médias (Fig. 4) e com pontos grossos lateralmente. Coxas anteriores aparentemente no mesmo nível que as médias em vista lateral (Fig. 4). Fêmur posterior cerca de 2,7 vezes tão longo quanto largo. Tíbia posterior com esporão lateral cerca de 1,6 vezes o comprimento do mediano, o primeiro artículo tarsal posterior cerca de 1,4 vezes 
tão longo quanto o esporão lateral e cerca de 2,4 vezes o esporão mediano. Pigídio do macho em forte declive e da fềmea em declive moderado. Quinto esterno abdominal visível suavemente emarginado no macho e arredondado na fêmea.

Terminália do macho (Figs 9, 10). Lobo médio (Fig. 9) com o comprimento 4,3 vezes a sua maior largura na região basal; valva ventral (Fig. 9-VV) com margens laterais retas; valva dorsal (Fig. 9-VD) com margens laterais côncavas e ápice truncado. Região basal do saco interno (Fig. 9-RB) sem escleritos anteriores; um esclerito médio (Fig. 9-EM) em forma de pequeno dente; um par de escleritos posteriores (Fig. 9-EP) subtriangulares, com um lado serreado. Região mediana do saco interno (Fig. 9-RM) com um par de escleritos laminares não sinuosos, serreados basal e sub-basalmente, os dentes aproximados (Fig. 9-EL); um esclerito longo em forma de forquilha (Fig. 9-EF) tão longo quanto os laminares, com hastes levemente separadas. Na região apical do saco interno um esclerito com hastes longas, gradativamente aproximadas (Fig. 9-EA). Região basal e mediana do saco interno com vários espinhos e dentículos, estes simples ou micro-serreados. Tégmen (Fig. 10) com emarginação moderada entre os lobos laterais alargados.

Discussão taxonômica. Amblycerus virescens sp.n., A. viridans sp.n., A. viridis sp.n. e $A$. virens (Jekel,1855) são semelhantes principalmente pela coloração geral do corpo. A. virescens sp.n. compartilha ainda com $A$. viridans sp.n. o metasterno não protuberante em vista lateral, na região das coxas médias (Fig. 4) e, coxas anteriores aparentemente no mesmo nível que as médias em vista lateral (Fig. 4). Todas as espécies citadas diferenciam-se pelo número, forma e tamanho dos escleritos do saco interno da terminália do macho.

Holótipo macho. BrasiL, Amazonas: Tapuruquara (Rio Negro) 4.5.II.1963, J. Bechyné leg., e, mais quatro parátipos: um com a etiqueta, Brasil: [Amapá] Porto Santana, 25-7-1961, J. \& B. Bechyné col.; dois com a etiqueta Brasil: [Amazonas] São Gabriel, 29.XI.27, Coleção J.F. Zikán e um com a etiqueta Brasil: Goiás, S. José do Tocantins, Rio São João, 22.VI.1942, F. Lane col.. Holótipo e um parátipo depositados no MZSP, um no MPEG, um no DZUP e um na FIOC.

Etimologia, O nome da espécie refere-se à coloração da pilosidade no corpo.

\section{Amblycerus viridans sp.n.}

Figs 11-15

Amblycerus viridans sp.n. é semelhante a $A$. virescens sp.n. exceto pelos seguintes caracteres:

Dimensões. Comprimento 4,17-4,42mm $(\bar{x}=4,25 \mathrm{~mm} ; \mathrm{n}=4)$; largura 2,75 $2,92 \mathrm{~mm}(\overline{\mathrm{x}}=2,83 \mathrm{~mm} ; \mathrm{n}=4)$.

Tegumento. Coloração geral preta exceto os três ou quatro primeiros artículos antenais, pigídio e abdome, rufos.

Índice ocular 2,6; sinus ocular 1/2,4 o diâmetro do olho; lobo pós-ocular $1 / 1,7$ vezes o maior comprimento do olho em vista lateral. Oitavo, nono e décimo artículos antenais cerca de 0,5 vezes tão longo quanto largo. Processo prosternal moderadamente expandido além das coxas anteriores. Escutelo cerca de 1,3 vezes 

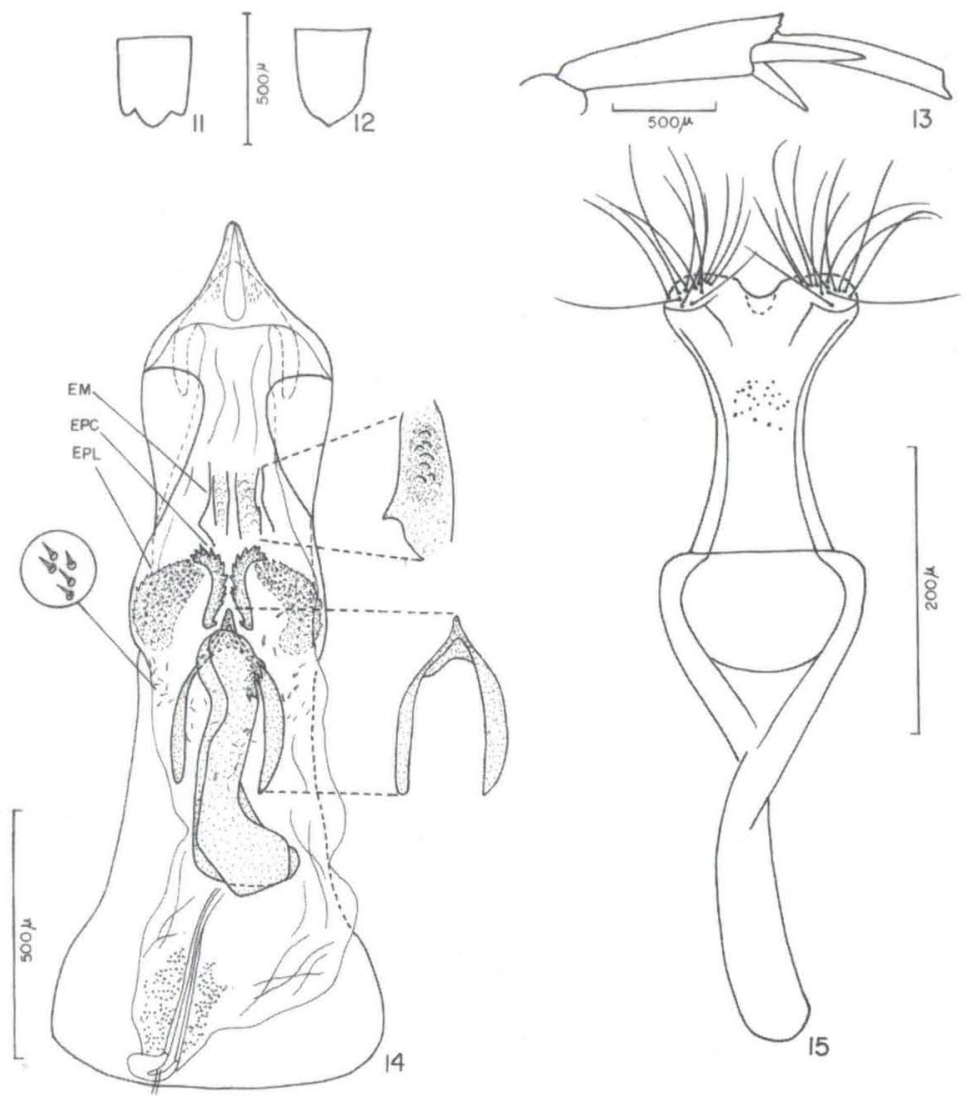

Figs 11-15. Amblycerus viridans sp.n. (11-12) Escutelo; (13) tibia e tarso posterior; (14-15) terminália do macho: (14) lobo médio, (15) tégmen. (EM) esclerito médio, (EPC) esclerito posterior central, (EPL) esclerito posterior lateral.

tão longo quanto largo, com ápice levemente tridentado (Fig. 11) ou unidentado (Fig. 12). Élitros com estrias fortemente impressas ou as medianas fracamente impressas, principalmente na metade apical. Fêmur posterior, cerca de 2,7 vezes tão longo quanto largo. Tíbia posterior (Fig. 13) com esporão lateral cerca de 1,7 vezes o comprimento do mediano, o primeiro artículo tarsal posterior cerca de 1,6 vezes tão longo quanto o esporão lateral e cerca de 2,6 vezes o esporão mediano.

Terminália do macho (Figs 14, 15). Lobo médio (Fig. 14) com o comprimento cerca de 3,6 vezes a sua maior largura na região basal; valva ventral com margens laterais côncavas; valva dorsal com margens laterais retas e ápice levemente acuminado. Região basal do saco interno com um par de escleritos médios (Fig. 14-EM) com pequenas protuberâncias arredondadas; dois pares de escleritos pos- 
teriores, o par central (Fig. 14-EPC) delgado, encurvado e com um lado serreado e o par lateral (Fig. 14-EPL) subovalado, formado por dentículos adensados. Região mediana do saco interno com um par de escleritos laminares moderadamente sinuosos, serreados na margem sub-basal, os dentes aproximados; um esclerito em forma de forquilha cerca de 0,7 vezes tão longo quanto os laminares, com hastes amplamente separadas. Na região apical do saco interno um esclerito com hastes muito longas. Região basal e mediana do saco interno sem dentículos; espinhos presentes na região mediana. Tégmen (Fig. 15) com emarginação suave entre os lobos laterais alargados.

Discussão taxonômica em A.virescens sp.n.

Holótipo macho. Brasil: [Mato Grosso] Chapada [dos Guimarães], nov.[ember], [H.H. Smith col.], Acc. No 2966, e, mais três parátipos com os mesmos dados do holótipo. Holótipo depositado no USNM, dois parátipos no $\mathrm{CMNH}$ e um no DZUP.

Etimologia. O nome da espécie refere-se à coloração da pilosidade no corpo.

\section{Amblycerus viridis sp.n.}

Figs 16-19

Amblycerus viridis sp.n. é semelhante a $A$. virescens sp.n. exceto pelos seguintes caracteres:

Dimensões. comprimento 4,58-5,33mm $(\bar{x}=4,75 \mathrm{~mm} ; n=10)$; largura 3,00$3,67 \mathrm{~mm}(\bar{x}=3,25 \mathrm{~mm} ; \mathrm{n}=10)$.

Tegumento. Coloração geral preta exceto os dois primeiros artículos antenais, pigídio e abdome, rufos.

Olhos levemente protraidos lateralmente (Fig. 16); índice ocular 3,0; sinus ocular 1/2,5 o diâmetro do olho. Oitavo, nono e décimo artículos antenais cerca de 0,9 vezes tão longo quanto largo. Processo prosternal não expandido além das coxas anteriores. Escutelo cerca de 0,9 ou 1,4 vezes tão longo quanto largo. Metasterno protuberante em vista lateral, na região das coxas médias (Fig. 17). Coxas anteriores (Fig. 17) nitidamente acima das coxas médias em vista lateral. Fêmur posterior (Fig. 18) cerca de 2,6 vezes tão longo quanto largo. Tíbia posterior (Fig. 18) com esporão lateral cerca de 2,0 vezes o comprimento do mediano, primeiro artículo tarsal posterior cerca de 1,5 vezes tão longo quanto o esporão lateral e cerca de 2,7 vezes o esporão mediano. Quinto esterno abdominal visível suavemente emarginado ou truncado no macho e truncado na fêmea.

Terminália do macho. Lobo médio (Fig. 19) com o comprimento 3,8 vezes a sua maior largura na região basal; valva ventral com margens laterais côncavas; valva dorsal com margens laterais retas, ápice levemente acuminado. Região basal do saco interno com um par de escleritos médios com pequenas protuberâncias arredondadas; um par de escleritos posteriores delgados, retos ou levemente encurvados e com um lado serreado. Região mediana do saco interno com um par de escleritos laminares moderadamente sinuosos, serreados na margem lateral quase até a metade do seu comprimento, os dentes aproximados; um esclerito em forma 
de forquilha cerca de 0,6 vezes tão longo quanto os laminares, com hastes retas ou encurvadas e amplamente separadas. Região basal e mediana do saco interno com espinhos e dentículos.
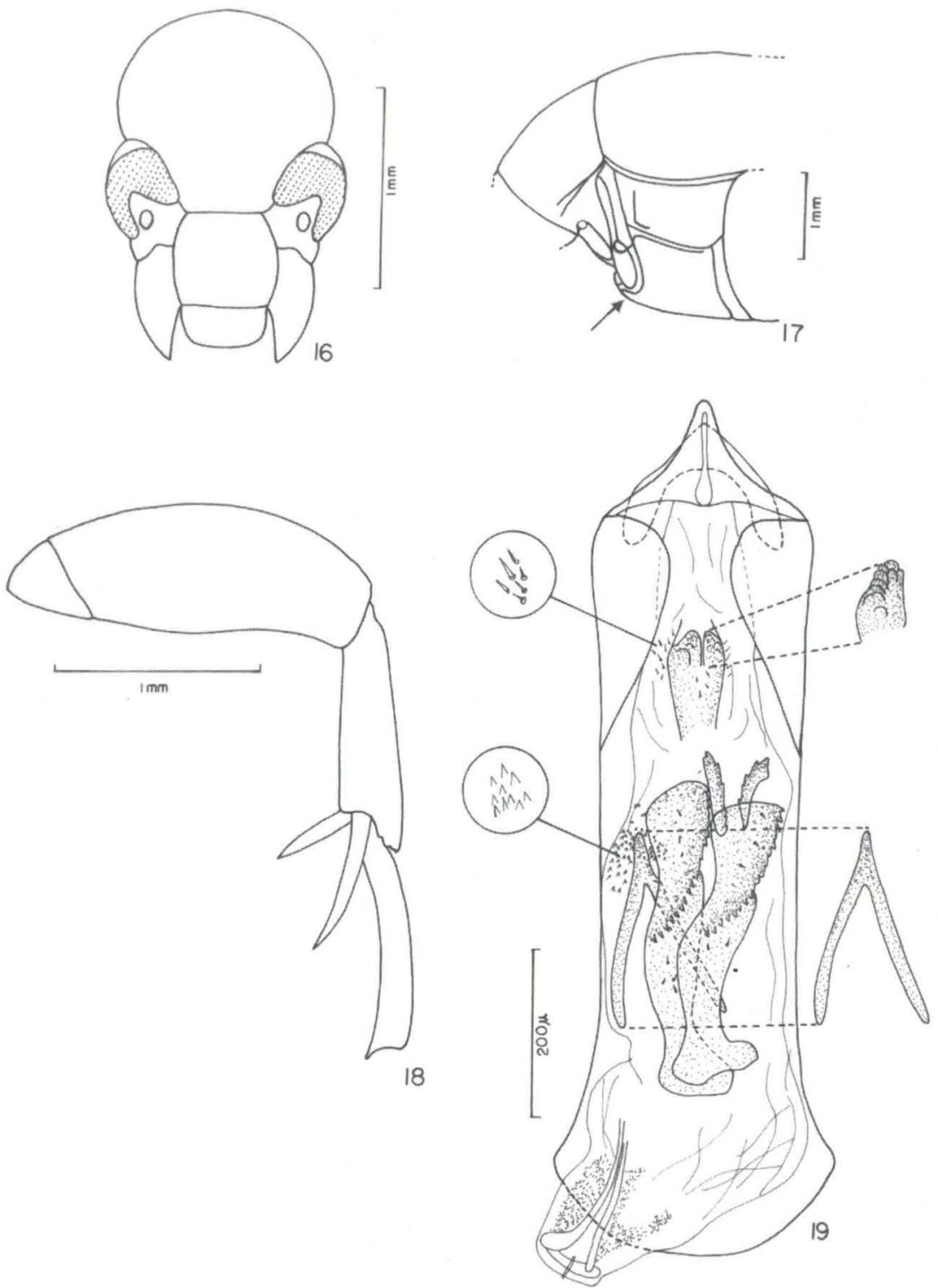

Figs 16-19. Amblycerus viridis, sp.n.. (16) Cabeça, vista frontal; (17) tórax, vista lateral; (18) perna posterior; (19) terminália do macho, lobo médio. 
Discussão taxonômica. Amblycerus viridis sp.n. mostra-se mais semelhante a A.virens pelo metasterno protuberante em vista lateral, na região das coxas médias (Fig. 17) e pelas coxas anteriores situadas em nível nitidamente acima das coxas médias em vista lateral (Fig. 17). A. viridis sp.n. diferencia-se de A. virens pelo fêmur posterior delgado (Fig. 18), cerca de 2,5-2,6 vezes tão longo quanto largo e ainda de $A$. virescens sp.n. e $A$. viridans sp.n. pelos olhos levemente protraídos lateralmente (Fig. 16). Outros comentários em $A$. virescens sp.n.

Holótipo macho. Brasil: [Mato Grosso], Chapada [dos Guimarães], nov. [ember], [H.H. Smith col.], Acc. № 2966, e, mais 11 parátipos com os mesmos dados do holótipo. Holótipo e sete parátipos depositados no $\mathrm{CMNH}$, dois parátipos no USNM e dois no DZUP.

Etimologia. O nome da espécie refere-se à coloração da pilosidade no corpo.

\section{Amblycerus megalobus sp.n.}

Figs 20-24

Dimensões. Comprimento 3,58-4,33mm $(\bar{x}=3,92 \mathrm{~mm} ; \mathrm{n}=10)$; largura 2,42$3,00 \mathrm{~mm}(\overline{\mathrm{x}}=2,58 \mathrm{~mm} ; \mathrm{n}=10)$.

Tegumento. Coloração geral preta exceto os três ou quatro primeiros artículos antenais, pigídio e abdome, rufos.

Pilosidade. Maior parte do corpo com pilosidade cinza entremeada com pêlos marrons dispersos ou em pequenos grumos, formando um padrão levemente manchado (Fig. 20). Escutelo geralmente cinza. Pigídio e abdome flavos com brilho dourado. Algumas vezes os apêndices exceto coxa posterior e região mediano-ventral do tórax com pilosidade cinza distribuída uniformemente.

Fronte levemente achatada. Olhos finamente facetados (11 omatídios), não protraídos lateralmente; índice ocular 3,3; sinus ocular 1/2,3 o diâmetro do olho; lobo pós-ocular 1/1,3 vezes o comprimento do olho em vista lateral (Fig. 21). Oitavo, nono e décimo artículos antenais cerca de 0,6 vezes tão longo quanto largo. Disco do pronoto sem pontos grossos. Processo prosternal moderadamente expandido além das coxas anteriores. Escutelo cerca de 1,1 vèzes tão longo quanto largo, com ápice levemente unidentado. Élitros com estrias medianas fracamente impressas, principalmente na metade apical. Eixo transversal do sulco metepisternal reto ou divergindo dorsalmente, eixo longitudinal curto, aproximadamente a metade do comprimento do metepisterno. Metasterno não protuberante em vista lateral na região das coxas médias e com pontos grossos lateralmente. Coxas anteriores aparentemente no mesmo nível que as médias em vista lateral. Fêmur posterior cerca de 2,5 tão longo quanto largo. Tíbia posterior (Fig. 22) com esporão lateral cerca de 2,5 vezes o comprimento do mediano, o primeiro artículo tarsal posterior cerca de 1,6 vezes tão longo quanto o esporão lateral e cerca de 2,6 vezes o esporão mediano. Pigídio do macho em forte declive e da fêmea em declive moderado. Quinto esterno abdominal visível suavemente emarginado ou truncado no macho e truncado na fêmea. 

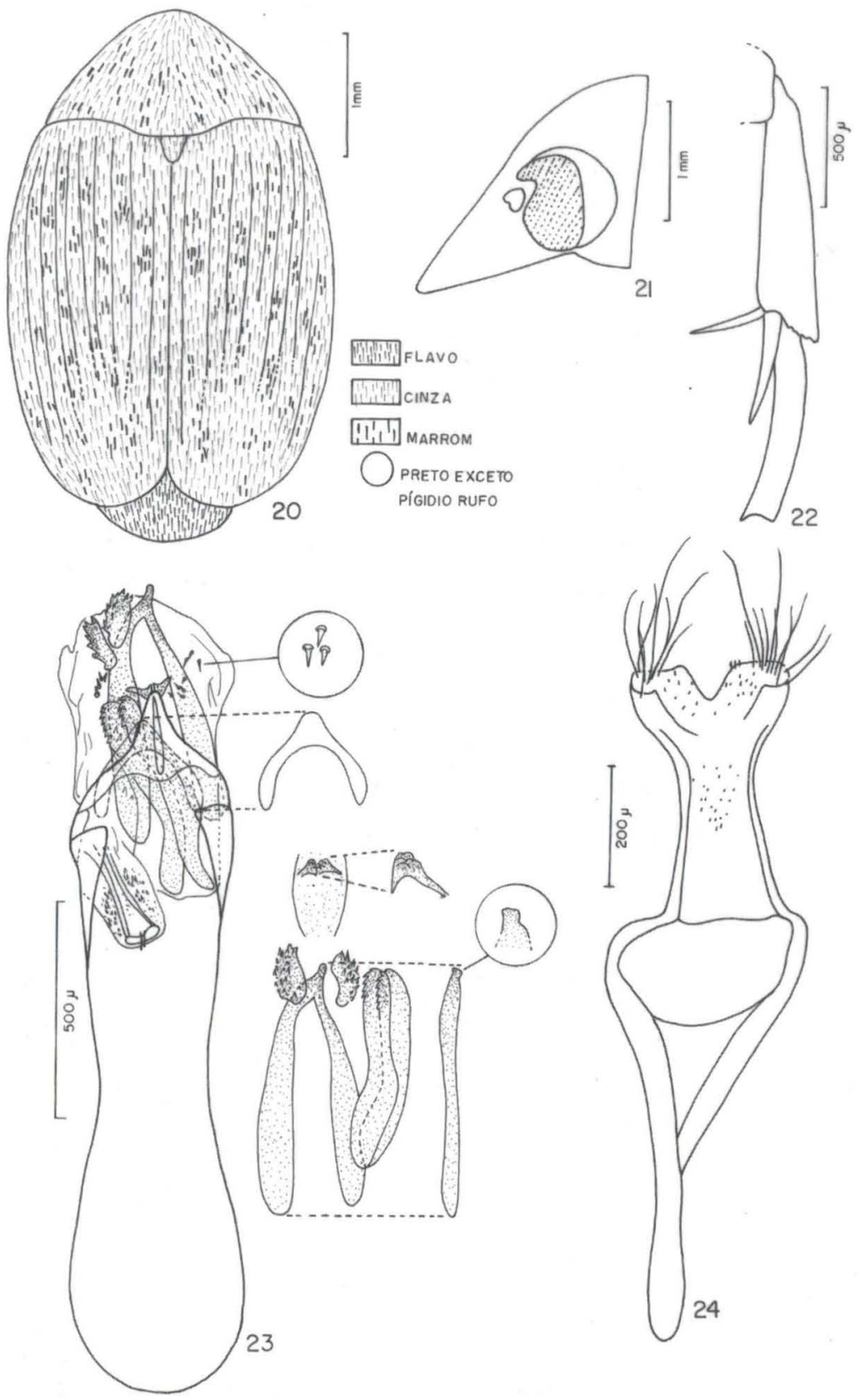

Figs 20-24. Amblycerus megalobus sp.n. (20) Padrão de coloração do tegumento (circulo) e pilosidade (retângulo) no dorso; (21) cabeça, vista lateral; $(22)$ tibia e tarso posterior; $(23,24)$ terminália do macho, (23) lobo médio, (24) tégmen. 
Terminália do macho (Figs 23, 24). Lobo médio (Fig. 23) com o comprimento cerca de 4,2 vezes a sua maior largura na região basal. Valva ventral do lobo médio com margens laterais côncavas; valva dorsal com margens laterais levemente côncavas e ápice arredondado. Região basal do saco interno sem escleritos anteriores; um par de pequenos escleritos médios com protuberâncias arredondadas; um par de escleritos posteriores subovalados e denticulados. Região mediana do saco interno com um par de escleritos laminares levemente arqueados e serreados na margem sub-basal, os dentes aproximados; um esclerito muito longo em forma de forquilha cerca de 1,3 vezes tão longo quanto os laminares, com hastes moderadamente separadas. Na região apical do saco interno um esclerito com hastes longas, gradativamente aproximadas. Região basal e mediana do saco interno com vários espinhos. Tégmen (Fig. 24) com emarginação moderada entre os lobos laterais alargados.

Discussão taxonômica. Amblycerus megalobus sp.n., A. multimaculatus (Pic, 1902) e A. atrogaster sp.n. mostram-se semelhantes principalmente pelo padrão de coloração do tegumento e pilosidade no dorso, exceto o pigídio. $A$. megalobus sp.n. ainda compartilha com A. multimaculatus a coloração do tegumento no abdome e pigídio diferente da dos élitros enquanto que em $A$. atrogaster sp.n. a coloração é semelhante. As citadas espécies distinguem-se facilmente pelo tamanho, número e forma dos escleritos do saco interno, da terminália do macho.

Holótipo macho. Brasil: [Mato Grosso], Chapada [dos Guimarães], nov. [ember], [H.H. Smith col.], Acc. № 2966, e, mais 75 parátipos; 68 com os mesmos dados do holótipo, exceto quatro com data de outubro e três de dezembro; dois com a etiqueta, Brasil: [Pará], Santarém, nov.[ember], [H.H. Smith col.], Acc. N² 2966; um com a etiqueta Brasil: [Mato Grosso], Corumbá, nov., [H.H. Smith col], Acc. No 2966; um com a etiqueta Brasil: [Pará], Taquara, oct. [ober], [H.H. Smith col.], Acc. No 2966; um com a etiqueta Brasil: [Pará], Santarém, 1919, S.M. Klages, Acc. $N^{\circ}$ 6324; um com a etiqueta Brasil: Santa Catarina, sem dados de coleta e um com a etiqueta Brasil: Mato Grosso, Chapada dos Guimarães, 18-I-1961, J. \& B.Bechyné col.. Holótipo e 62 parátipos depositados no $\mathrm{CMNH}$, cinco parátipos no DZUP, um no MPEG, um no MCZC e sete no USNM.

Etimologia. O nome refere-se ao lobo pós-ocular que é o maior dentre as espécies brasileiras conhecidas.

\section{Amblycerus atrogaster sp.n.}

(Figs 25-29)

A.atrogaster sp.n. é semelhante a A.megalobus sp.n. exceto pelos seguintes caracteres:

Dimensões. Comprimento $3,08-4,17 \mathrm{~mm}(\overline{\mathrm{x}}=3,50 \mathrm{~mm} ; \mathrm{n}=4)$; largura 2,00$2,75 \mathrm{~mm}(\overline{\mathrm{x}}=2.33 \mathrm{~mm} ; \mathrm{n}=4)$.

Tegumento. Coloração geral preta exceto os quatro ou cinco primeiros artículos antenais, fulvos.

Pilosidade. Cabeça, apêndices (exceto coxa posterior) e região mediano-ven- 

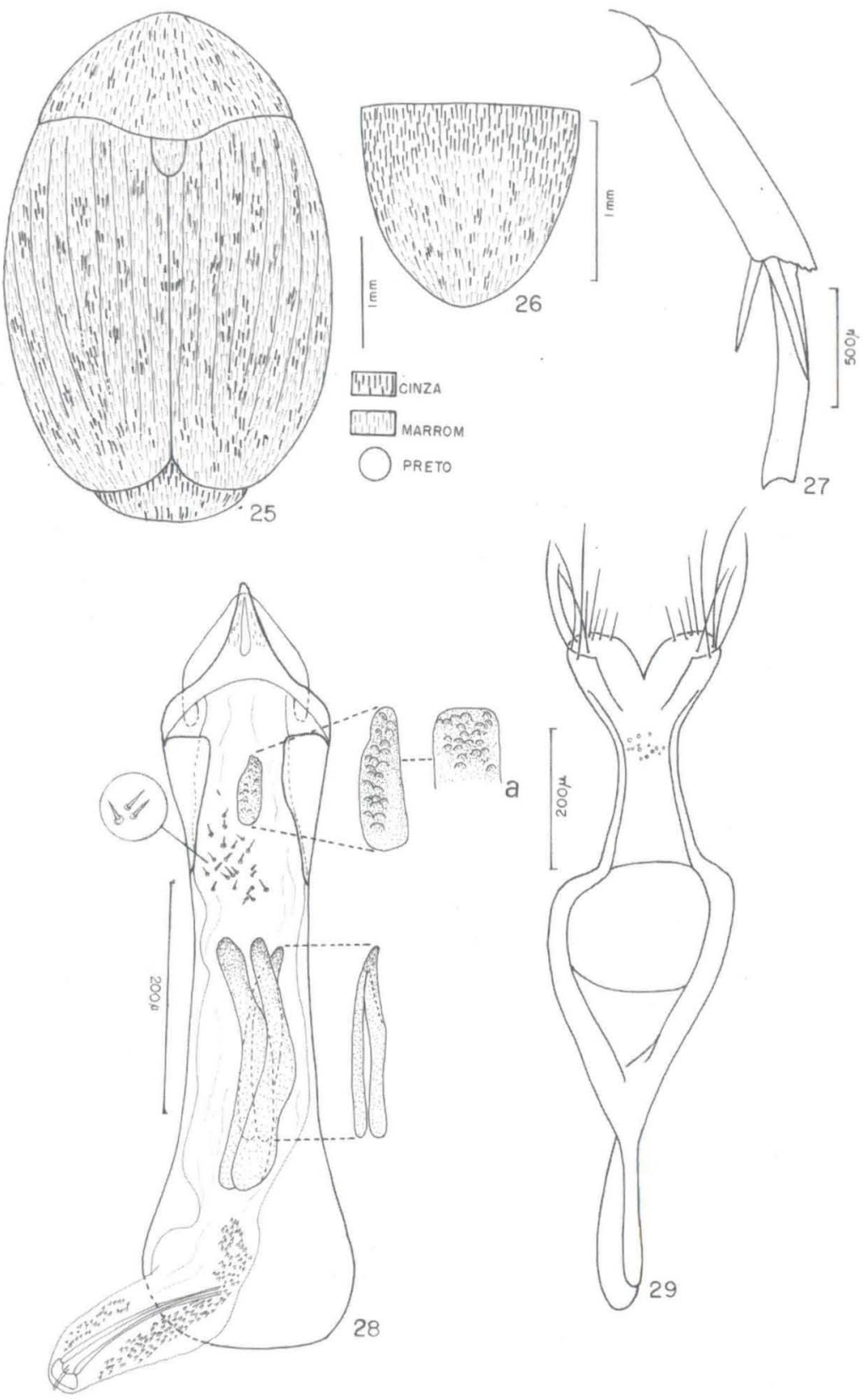

Figs 25-29. Amblycerus atrogaster sp.n. (25-26) Padrão de coloração do tegumento (circulo) e pilosidade (retângulo), (25) vista dorsal, (26) pigidio; (27) tíbia e tarso posterior; $(28,29)$ terminália do macho, (28) lobo médio, (29) tégmen. (a) variação intraespecífica. 
tral com pilosidade cinza distribuída uniformemente. Restante do corpo exceto escutelo e pigídio com pilosidade marrom entremeada com pilosidade cinza dispersa ou em pequenos grumos formando um padrão manchado (Fig. 25). Escutelo cinza. Pigídio (Fig. 26) na região basal e áreas ântero-laterais com pilosidade cinza adensada com suave brilho dourado e no restante pilosidae marrom com alguns grumos cinza.

Olhos finamente facetados (12 omatídios). Índice ocular 2,9; sinus ocular 1/3,0 o diâmetro do olho; lobo pós-ocular 1/1,2 vezes o maior comprimento do olho em vista lateral. Oitavo, nono e décimo artículos antenais cerca de 0,5 vezes tão longo quanto largo. Processo prosternal levemente expandido além das coxas anteriores. Escutelo cerca de 1,3 vezes tão longo quanto largo, com ápice arredondado. Eixo longitudinal do sulco metepisternal muito curto, menos que a metade do comprimento do metepisterno. Fêmur posterior cerca de 2,6 vezes tão longo quanto largo. Tíbia posterior (Fig. 27) com esporão lateral cerca de 1,4 vezes o comprimento do mediano, o primeiro artículo tarsal posterior cerca de 1,7 vezes tão longo quanto o esporão lateral e cerca de 2,4 vezes o esporão lateral. Pigídio do macho e da fêmea em forte declive. Quinto esterno abdominal visível suavemente emarginado no macho e truncado na fềmea.

Terminália do macho (Figs 28, 29). Lobo médio (Fig. 28) com o comprimento 4,5 vezes a sua maior largura na região basal; valva ventral com margens laterais côncavas; valva dorsal com margens laterais retas, ápice arredondado ou levemente acuminado. Região basal do saco interno sem escleritos anteriores e posteriores; um esclerito médio alongado ou subquadrado (Fig. 28a), com pequenas protuberâncias arredondadas. Região mediana do saco interno com um par de escleritos laminares lisos e levemente arqueados; um esclerito em forma de forquilha cerca de 0,7 vezes tão longo quanto os laminares, com hastes muito aproximadas. $\mathrm{Na}$ região apical do saco interno um esclerito com hastes muito longas, gradativamente convergentes. Região basal do saco interno com vários espinhos. Tégmen (Fig. 29) com recorte em "V" entre os lobos laterais alargados.

Discussão taxonômica em A. megalobus sp.n.

Holótipo macho. Brasil: [Pará], Santarém, sem data de coleta, [H.H.Smith col.], Acc. $\mathrm{N}^{\circ}$ 2966, e, mais quatro parátipos com a etiqueta, Bolívia: Loma Alta, 19.May.1957, G.Pinckert col. Holótipo depositado no CMNH, dois parátipos no USNM e dois no DZUP.

Etimologia. O nome da espécie refere-se à coloração preta do tegumento no abdome.

\section{Amblycerus chapadicola sp.n.}

(Figs 30-33)

Dimensões. Comprimento $3,75-4,42 \mathrm{~mm}(\overline{\mathrm{x}}=4,17 \mathrm{~mm} ; \mathrm{n}=4)$; largura 2,50$2,92 \mathrm{~mm}(\overline{\mathrm{x}}=2,83 \mathrm{~mm} ; \mathrm{n}=4)$.

Tegumento. Coloração geral testácea. Cabeça, do quinto ao $11^{\circ}$ artículos antenais, região ventro-mediana do tórax e pernas exceto coxa posterior, muito escuros à pretos. Algumas vezes metepisterno e coxa posterior também escurecidos. 

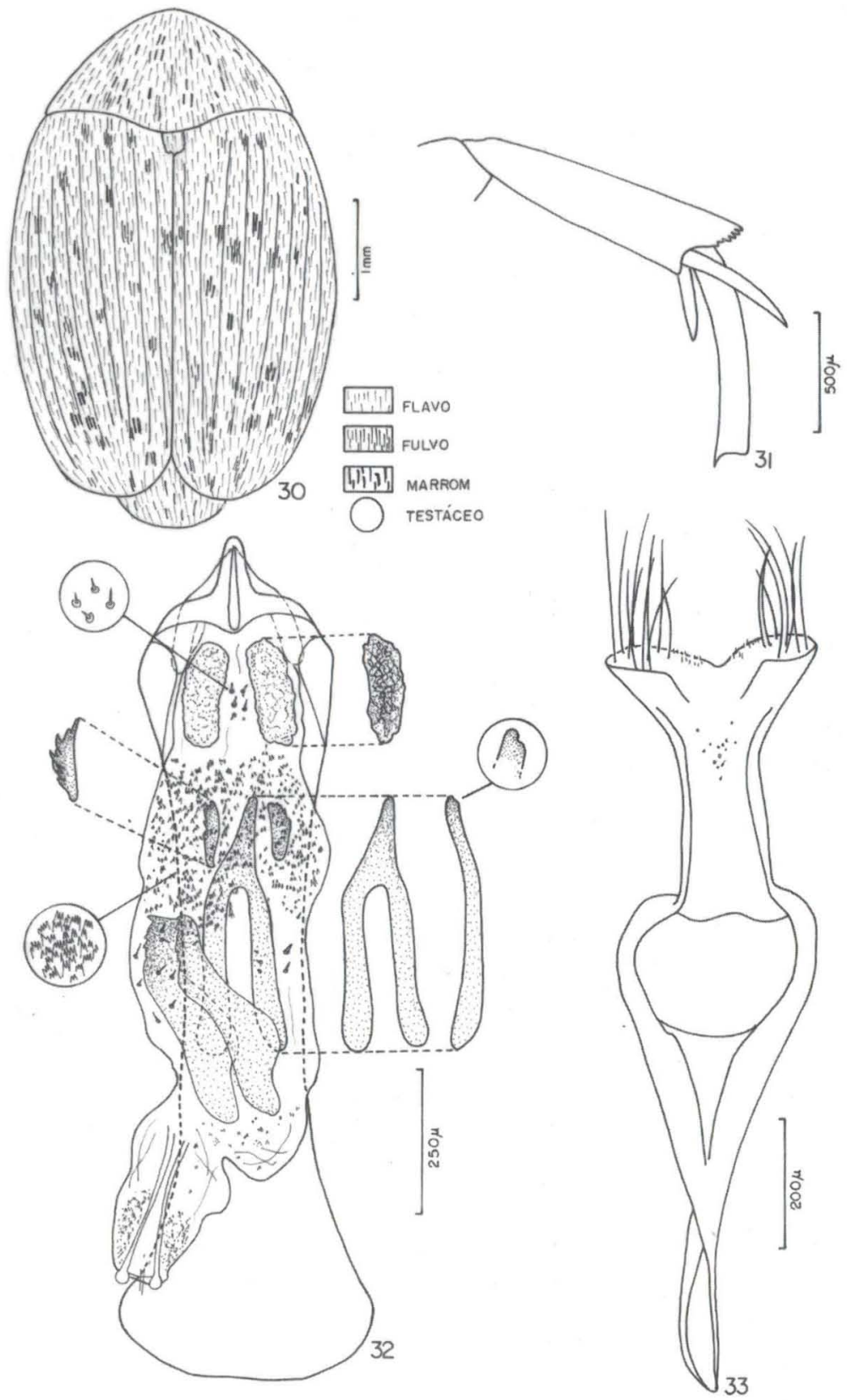

Figs 30-33. Amblycerus chapadicola sp.n.. (30) Padrão de coloração do tegumento (círculo) e pilosidade (retângulo) no dorso; (31) tíbia e tarso posterior; (32-33) terminália do macho: (32) lobo médio, (33) tégmen. 
Pilosidade. Cabeça, apêndices (exceto coxa posterior) e região mediano-ventral do tórax e abdome com pilosidade flava distribuída uniformemente. Restante do corpo com pilosidade flava entremeada com pêlos fulvos claros e marrons formando suave padrão manchado (Fig. 30). Fronte levemente achatada. Olhos finamente facetados (10 omatídios), não protraídos lateralmente; índice ocular 3,0; sinus ocular $1 / 3,0$ o diâmetro do olho; lobo pós-ocular $1 / 1,7$ vezes o maior comprimento do olho em vista lateral. Oitavo, nono e décimo artículos antenais cerca de 0,6 vezes tão longo quanto largo. Disco do pronoto sem pontos grossos. Processo prosternal levemente expandido além das coxas anteriores. Escutelo cerca de 1,6 vezes tão longo quanto largo, com ápice levemente tridentado. Élitros com estrias fortemente impressas ou as medianas fracamente impressas, principalmente na metade apical. Eixo transversal do sulco metepisternal divergindo dorsalmente, eixo longitudinal muito curto, menos que a metade do comprimento do metepisterno. Metasterno não protuberante em vista lateral, na região das coxas médias e com pontos grossos lateralmente. Coxas anteriores aparentemente no mesmo nível que as médias em vista lateral. Fêmur posterior cerca de 2,8 vezes tão longo quanto largo. Tíbia posterior (Fig. 31) com esporão lateral cerca de 1,7 vezes o comprimento do mediano, primeiro artículo tarsal posterior cerca de 1,7 vezes tão longo quanto o esporão lateral e cerca de 3,0 vezes o esporão mediano. Pigídio do macho e da fêmea em forte declive. Quinto esterno abdominal visível suavemente emarginado no macho e arredondado na fêmea.

Terminália do macho (Figs 32, 33). Lobo médio (Fig. 32) com o comprimento 4,3 vezes a sua maior largura na região basal; valva ventral com margens laterais côncavas; valva dorsal com margens laterais levemente côncavas, ápice levemente acuminado. Região basal do saco interno com um par de escleritos anteriores sub-retangulares com pequenas protuberâncias irregulares; escleritos médios ausentes; um par de escleritos posteriores pequenos e denticulados. Região mediana do saco interno com um par de escleritos laminares moderadamente sinuosos, serreados na margem sub-basal, os dentes aproximados; um esclerito em forma de forquilha cerca de 1,2 vezes tão longo quanto os laminares, com hastes moderadamente separadas. Na região apical do saco interno um esclerito com hastes longas, gradativamente aproximadas. Região basal e mediana do saco interno com vários espinhos e na região mediana com dentículos simples ou micro-serreados adensados. Tégmen (Fig. 33) com emarginação suave entre os lobos laterais alargados.

Discussão taxonômica. As espécies Amblycerus chapadicola sp.n e A. mourei sp.n. são semelhantes principalmente pela coloração da pilosidade no dorso. O número, forma e tamanho dos escleritos do saco interno da terminália do macho contribuem para a separação destas espécies.

Holótipo macho. Brasil: [Mato Grosso], Chapada [dos Guimarães], nov. [ember], [H.H. Smith col.], Acc. N ${ }^{0} 2966$, e, mais três parátipos com os mesmos dados do holótipo. Holótipo e um parátipo depositados no $\mathrm{CMNH}$, um parátipo no USNM e um no DZUP.

Etimologia. O nome da espécie refere-se à localidade-tipo. 


\section{Amblycerus mourei sp.n.}

Figs 34-36

Amblycerus mourei sp.n. é semelhante a A. chapadicola sp.n. exceto pelos seguintes caracteres:

Dimensões. Comprimento $3,50-5,08 \mathrm{~mm}(\overline{\mathrm{x}}=4,08 \mathrm{~mm} ; \mathrm{n}=10)$; largura 2,33$3,50 \mathrm{~mm}(\overline{\mathrm{x}}=2,67 \mathrm{~mm} ; \mathrm{n}=10)$.

Pilosidade. Corpo com pilosidade flava distribuída uniformemente; pêlos marrons dispersos ou em raros grumos. Nas áreas de tegumento escuro, pilosidade mais clara.

Olhos levemente protraídos lateralmente; índice ocular 2,7; sinus ocular $1 / 2,6$ o diâmetro do olho; lobo pós-ocular $1 / 3,0$ vezes o maior comprimento do olho em vista lateral. Oitavo, nono e décimo artículos antenais cerca de 0,8 vezes tão longo quanto largo. Disco do pronoto com pontos grossos menores que os pontos grossos das laterais. Escutelo cerca de 1,4 vezes tão longo quanto largo. Élitros com estrias fortemente impressas. Eixo transversal do sulco metepisternal reto ou divergindo dorsalmente. Fêmur posterior cerca de 2,4 vezes tão longo quanto largo. Tíbia posterior (Fig. 34) com esporão lateral cerca de 2,0 vezes o comprimento do mediano, o primeiro artículo tarsal posterior cerca de 1,6 vezes tão longo quanto o esporão lateral. Quinto esterno abdominal visível truncado no macho e arredondado na fêmea.

Terminália do macho (Figs 35, 36). Lobo médio (Fig. 35) com o comprimento 4,0 vezes a sua maior largura na região basal; valva ventral com margens laterais côncavas; valva dorsal com margens laterais retas, ápice arredondado. Região basal do saco interno sem escleritos anteriores e posteriores; dois pares de escleritos médios, um par (raramente um esclerito) em forma de dente conforme a figura 35-a,b e c e outro delgado com um lado serreado. Região mediana do saco interno com um par de escleritos laminares não sinuosos, serreados nas margens basal e sub-basal, os dentes aproximados; um esclerito em forma de forquilha aproximadamente tão longo quanto os laminares. Região basal e mediana do saco interno com espinhos. Tégmen (Fig. 36) com emarginação moderada entre os lobos laterais alargados.

Discussão taxonômica em A. chapadicola sp.n.

Holótipo macho. BrasiL, Minas Gerais: Pedra Azul (800m) XI.1972, M. Alvarenga leg., e mais 16 parátipos; quatro com os mesmos dados do holótipo; cinco com a etiqueta Brasil: [Mato Grosso], Chapada [dos Guimarães], nov. [ember], [H.H. Smith col.] e oito com a etiqueta Brasil: Santa Catarina, sem dados de coleta. Holótipo e seis parátipos depositados no $\mathrm{CMNH}$, dois parátipos no DZUP, oito no MCZC e um no USNM.

Etimologia. O nome da espécie em homenagem ao Pe. Jesus S. Moure. 

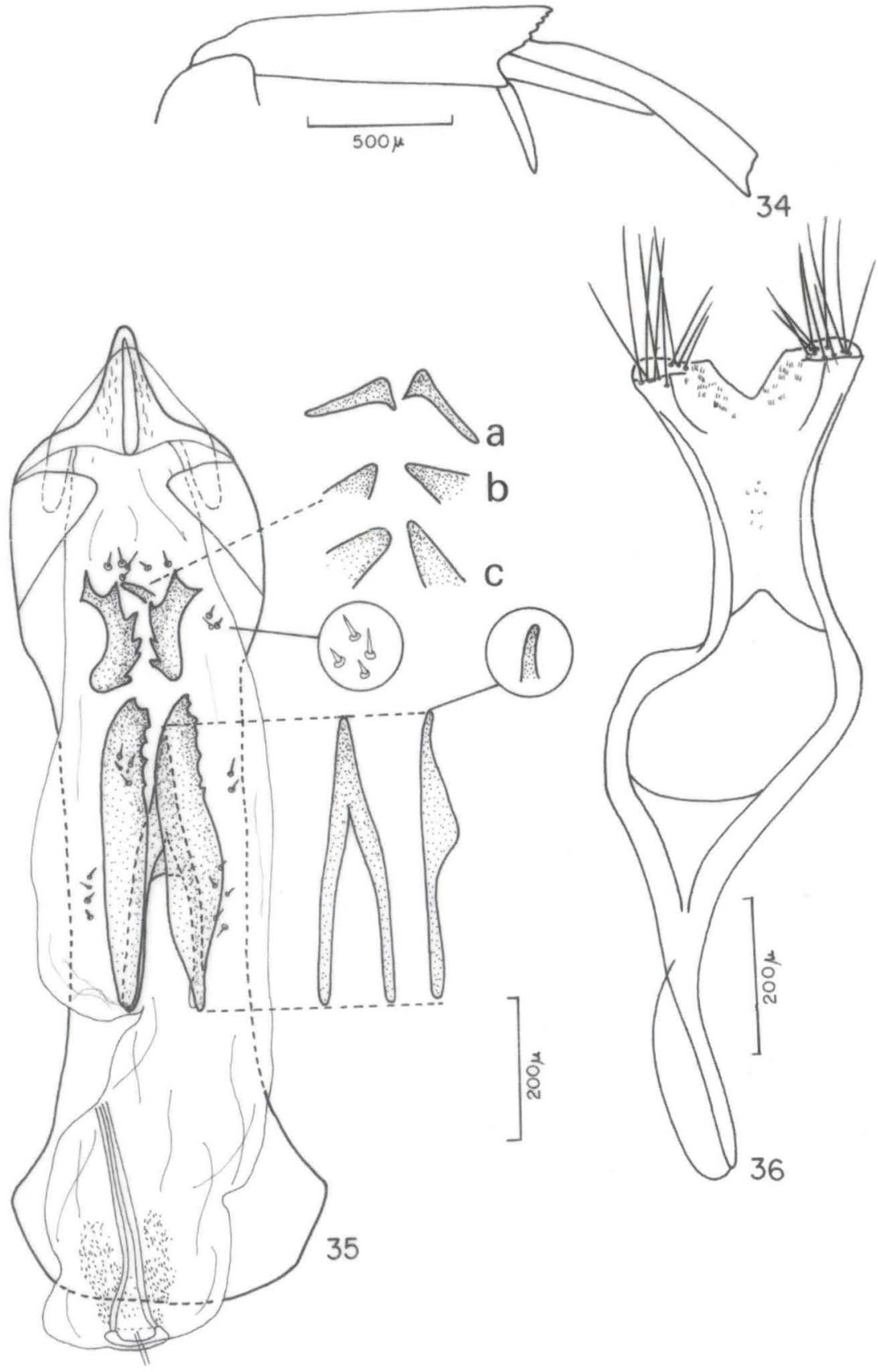

Figs 34-36. Amblycerus moureisp.n.. (34) Tíbia e tarso posterior; (35-36) terminália do macho: (35) lobo médio, (36) tégmen. $(a, b, c)$ variação intraespecifica. 


\section{Amblycerus danunciae sp.n.}

Figs $37-43$

\section{Dimensões. Comprimento 4,67mm; largura 3,00mm.}

Tegumento. Coloração geral testácea. Antenas, pernas anteriores e médias, mais claras. Pronoto, élitros, região ventral do tórax e perna posterior com manchas irregulares escurecidas (Fig. 37). Pigídio com uma pequena mácula central, preta (Fig. 37).

Pilosidade. Cabeça, escutelo, região mediano-ventral do tórax e abdome com pilosidade flava distribuída uniformemente. Restante do corpo com pilosidade fulva entremeada com pêlos flavos a brancos formando um padrão suavemente manchado; pêlos marrons em pequenos e raros grumos (Fig. 37). No pronoto pêlos flavos adensados em duas faixas oblíquas mediano-laterais, separadas por faixa mediana.

Fronte convexa. Olhos grossamente facetados ( 8 omatídios), moderadamente protraídos lateralmente (Fig. 38); índice ocular 3,3; sinus ocular 1/3,0 o diâmetro do olho; lobo pós-ocular $1 / 4,0$ vezes o maior comprimento do olho em vista lateral (Fig. 39). Oitavo, nono e décimo artículos antenais cerca de 0,8 vezes tão longo quanto largo. Disco do pronoto sem pontos grossos. Processo prosternal levemente expandido além das coxas anteriores. Escutelo cerca de 1,5 vezes tão longo quanto largo, com ápice levemente tridentado (Fig. 42). Élitros com estrias fortemente impressas. Eixo transversal do sulco metepisternal divergindo dorsalmente, eixo longitudinal muito curto, menos que a metade do comprimento do metepisterno. Metasterno não protuberante em vista lateral, na região das coxas médias e sem pontos grossos lateralmente. Coxas anteriores aparentemente no mesmo nível que as médias em vista lateral. Fêmur posterior cerca de 2,7 vezes tão longo quanto largo. Tíbia posterior (Fig. 40) com esporão lateral cerca de 2,0 vezes o comprimento do mediano, o primeiro artículo tarsal posterior cerca de 1,5 vezes tão longo quanto o esporão lateral e cerca de 2,6 vezes o esporão mediano. Pigídio do macho em forte declive. Quinto esterno abdominal visível truncado no macho. Fêmea não conhecida.

Terminália do macho (Figs 42, 43). Lobo médio (Fig. 42) com o comprimento 4,2 vezes a sua maior largura na região basal; valva ventral com margens laterais côncavas; valva dorsal com margens laterais levemente côncavas, ápice levemente acuminado. Região basal do saco interno sem escleritos anteriores; um par de escleritos médios com pequenas protuberâncias arredondadas; um par de escleritos posteriores delgados, convexos e com um dos lados serreado. Região mediana do saco interno com um par de escleritos laminares levemente sinuosos, serreados nas margens basal e sub-basal, os dentes aproximados; um esclerito em forma de forquilha tão longo quanto os laminares, com hastes moderadamente separadas e mais um par de pequenos escleritos delgados, convexos e com um dos lados serreado. $\mathrm{Na}$ região apical do saco interno um esclerito com hastes muito longas, gradativamente aproximadas. Região basal e mediana do saco interno com vários espinhos. Tégmen (Fig. 43) com emarginação suave entre os lobos laterais alargados. 

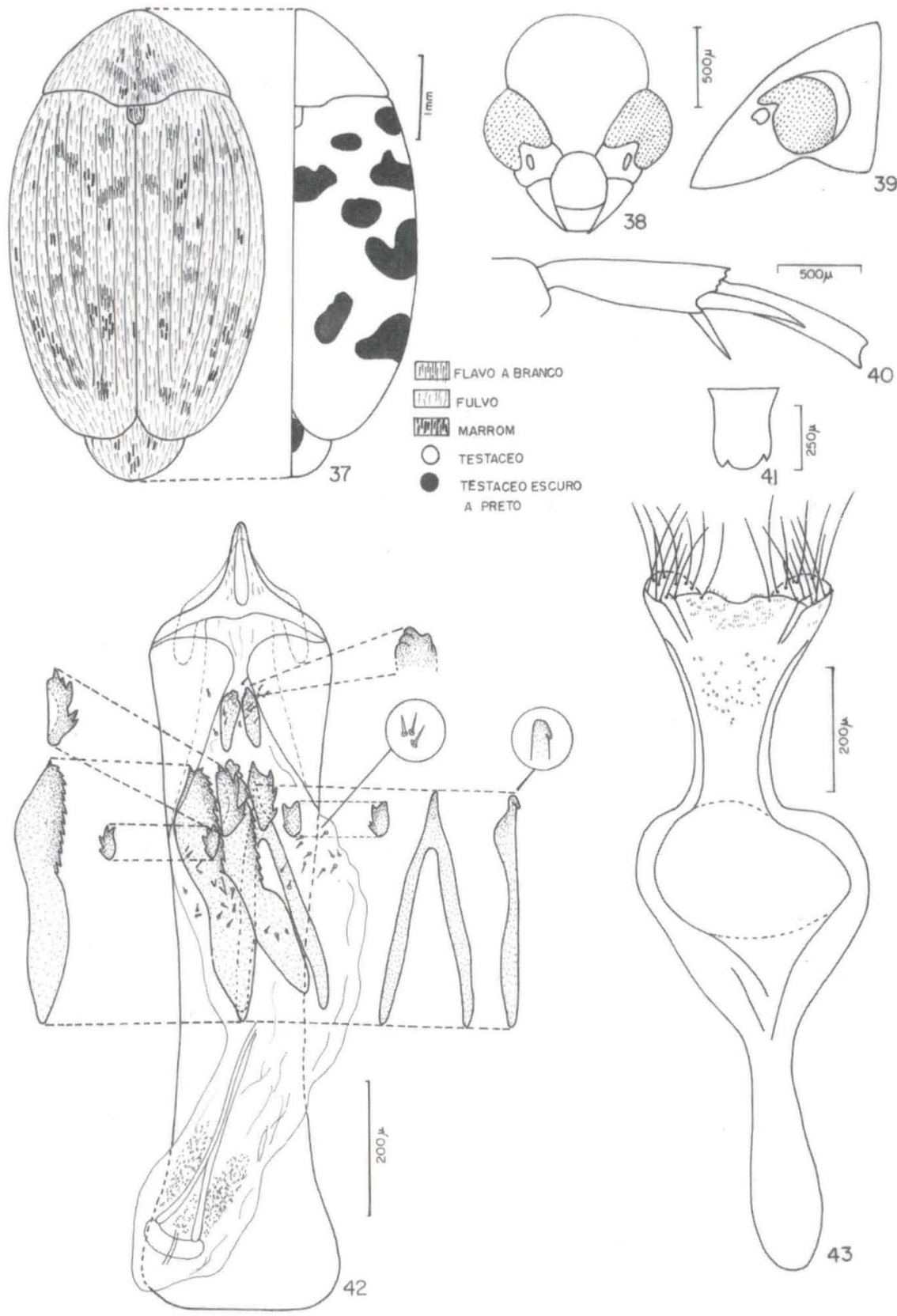

Figs 37-43. Amblycerus danunciae sp.n. (37) Padrão de coloração do tegumento (circulo) e pilosidade (retângulo) no dorso; (38) cabeça, vista frontal; (39) cabeça, vista lateral; (40) tíbia e tarso posterior; (41) escutelo; (42-43) terminália do macho, (42) lobo médio, (43) tégmen. 
Discussão taxonômica. Esta espécie não se mostra semelhante a outras do gênero e pode ser diferenciada principalmente pela coloração no dorso. Comparando-se com as espécies aqui descritas diferencia-se pela fronte convexa, olhos grossamente facetados (8 omatídios) e moderadamente protraídos, lobo pós-ocular $1 / 4,0$ vezes o maior comprimento do olho em vista lateral e metasterno sem pontos grossos lateralmente.

Holótipo macho. Brasil: Goiás, Aragarças, 12.IV.1953, Sick col., depositado no MZSP.

Etimologia. O nome da espécie em homenagem à Dra. Danúncia Urban.

AGRADECIMENTOS. Ao Dr.John M.Kingsolver pelo acesso às notas sobre os tipos de Amblycerus, ao Pe.Jesus S. Moure pelas sugestões na elaboração dos nomes de espécies novas e a Dra.Danúncia Urban pela revisão do manuscrito.

\section{REFERÊNCIAS BIBLIOGRÁFICAS}

Kingsolver, J.M. 1970. A study of male genitalia in Bruchidae (Coleoptera). Proc. ent. Soc. Wash. 72 (3): 370-386.

1991. A new species of Amblycerus (Coleoptera: Bruchidae) from Central and South America, with notes on its biology. Proc. ent. Soc. Wash. 93 (2): 433-436.

RiBeIro-CostA, C.S. 1993. Two new species of Amblycerus Thunberg from Brazil (Coleoptera, Bruchidae). Revta bras. Zool. 9 (1/2): 5-9. [1992].

Ribeiro-Costa, C.S. \& J.M. Kingsolver. 1993a. A new species of Amblycerus Thunberg, 1815 (Coleoptera: Bruchidae) and a lectotype designation. Insecta Mundi 6 (3): 183-187.

. 1993b. Amblycerus teutoniensis (Coleoptera: Bruchidae), a new species of seed beetle. Ent. News 104 (4): 160-164.

Recebido em 16.I.1997; aceito em 04.IX.1997. 